\title{
Hepatic Pain, CTCAE
}

National Cancer Institute

\section{Source}

National Cancer Institute. Hepatic Pain, CT CAE. NCI Thesaurus. Code C143542.

A disorder characterized by a sensation of marked discomfort in the liver region. 